\title{
The Effect of Deposition Rate on the Electrical Properties of Indium Tin Oxide (ITO) Thin Films
}

\author{
Hadaate Ullah ${ }^{1}$, Shahin Mahmud ${ }^{* 2}$, Fahmida Sharmin Jui ${ }^{3}$ \\ ${ }^{1,2}$ Dept. of Electrical and Electronic Engineering (EEE), Southern university Bangladesh, \\ 739/A, Mehedibag Road, Chittagong. Phone: +8802869343 (Ext. -202) \\ ${ }^{3}$ Dept. of Electronics and Communication Engineering (ECE), Southern university Bangladesh, \\ 739/A, Mehedibag Road, Chittagong. Phone: +8802869343 (Ext. -202) \\ ${ }^{*}$ Corresponding author, e-mail: sendbablu_apee@yahoo.com ${ }^{1}$, shahin@southern.edu.bd ${ }^{2}$, \\ fahmida_apece@yahoo.com ${ }^{3}$
}

\begin{abstract}
Indium-tin oxide (ITO) which is optically transparent is referred as a "universal" electrode for various optoelectronic devices such as organic light emitting diodes (OLEDs). It is scientifically proved that the performance of OLEDs raises up significantly by exposing the ITO surface to oxygen plasma. This study employs conducting atomic force microscopy (C-AFM) for unique nanometer-scale mapping of the local current density of a vapor-deposited ITO film. Indium Tin Oxide (ITO) thin films have been prepared by using the reactive evaporation method on glass substrates in an oxygen atmosphere. It is found that the deposition rate plays a vital role in controlling the electrical properties of the ITO thin films. The resistivity and the electrical conductivity were also investigated. The electrical resistivity of $3.10 \times 10^{-6} \Omega \mathrm{m}$ has been obtained with a deposition rate of $2 \mathrm{~nm} / \mathrm{min}$.
\end{abstract}

Keywords: resistivity, conductivity, indium tin oxide, evaporation, deposition etc

Copyright $\odot 2015$ Institute of Advanced Engineering and Science. All rights reserved.

\section{Introduction}

Tin-doped indium oxide (ITO) is frequently used as an electrode in various optoelectronic devices. For example, flat panel displays, solar cells, and organic electroluminescence devices. This increased demand is because of its unique combination of properties, including high optical transparency, low electrical resistance, and excellent surface adhesion [1]. The surface electronic properties which are used to find out the interfacial charge transport are affected by the chemical compositions. In turn, the performance of optoelectronic devices constructed with ITO electrodes is limited by the spatial heterogeneity of the surface electronic structure of ITO. For this reason, nanometer-scale measurement of ITO's surface electronic (i.e., I/V) characteristic is necessary to expose the heterogeneity.

The interest in transparent conductors has increased vastly since the first report of Badeker on transparent conducting cadmium oxide films (1907) [2]. These materials are used in various purposes such as liquid crystal displays, transparent electrodes for solar cells, gas sensors, photo detectors and laser damage resistant coatings in high power laser technology [3]. The creation of electron degeneracy in wide band gap $(\geq 3 \mathrm{eV})$ oxides by applying nonstoichiometry or appropriate dopants is must for the simultaneous occurrence of high optical transparency $(\approx 90 \%)$ in the visible region together with high electrical conductivity. Various oxides of indium, tin, cadmium, zinc and in combinations can be used to fulfill the conditions. A great deal of basic research and development has been carried out on the electrical and optical properties of indium oxide based materials because of its technological importance. Rupprecht [4] was the pioneer of investigations on the indium oxide $\left(\ln _{2} \mathrm{O}_{3}\right)$. After that different techniques have been used for the preparation of these oxide films [5-7]. To increase the conductivity of these films, various types of dopants such as tin, cadmium, antimony and fluorine can be introduced. As they have enhanced electrical and optical quality compared to other transparent conductors, attention has been given to the study of tin doped indium oxide (ITO) films. ITO is an $\mathrm{In}_{2} \mathrm{O}_{3}$ based material that has been doped with $\mathrm{Sn}$ to increase the electrical conductivity. Here tin plays the role of cationic doping in the $\ln _{2} \mathrm{O}_{3}$ lattice and substitute on the indium sites to join with the interstitial oxygen. 
Indium tin oxide (ITO) films have been widely researched over the past many years since they started to exhibit electrically conductive and optically transparent characteristics. For this reason, ITO films are widely used as coating electrodes in optoelectonic devices [8-10], electrolumniscent devices [11], and photo voltaic cells [12], electrochromic devices [13], liquid crystal displays [14] and energy efficient windows [15]. Indium tin oxide thin films can be prepared by many ways including RF or dc sputtering [16], spray pyrolysis [17], reactive thermal evaporation [18], electron beam gun evaporation [19] and laser ablation [20]. Most of the time the investigations on ITO are carried out on sputter deposited films whereas the fewer studies have been conducted on thermally evaporated ITO films. The knowledge of structural, electrical and optical properties is still limited and much more investigations are mandatory to understand the physical characteristics of these films. In this study, the investigations of the optoelectric properties of ITO thin films have been found significantly depend on the deposition parameters such as substrate temperature and deposition rate. We have found that instead of being an important parameter, the deposition rate is always being neglected in the investigations of optoelectric properties of ITO thin films. This paper reports the studies on the electrical properties of ITO thin films evaporated by thermal evaporation at different deposition rates.

\section{Experimental Descriptions}

The evaporation of indium tin oxide (ITO) thin films is perfomed by using a 12-inch vacuum coating unit with an electron beam gun. A pestle and mortar is used to mix spectroscopically pure indium oxide powder $(99.99 \%)$ and tin oxide powder $(99.99 \%)$ taken in wt $\%$ proportions perfectly. The mixture was sintered in a furnace for 6 hours at a temperature of $800^{\circ} \mathrm{C}$. The mixture was pressed into pellets to make the source material for evaporation. Primarily, the vacuum chamber was evacuated to a base pressure of $10^{-6} \mathrm{mbar}$. Pure oxygen was entered to the chamber with the high vacuum opened valve. To reach a steady state chamber pressure, the needle valve of the bell jar of the coating unit should be adjusted. A calibrated chromal alumal thermocouple was attached on the glass slides which were used as the substrates. The substrates were cleaned by using the standard cleaning technique. The substrates were subjected to ionic bombardment inside the bell jar for 5 minutes as the final cleaning before deposition. The rate of evaporation was limited within the range 2 to $10 \mathrm{~nm} / \mathrm{min}$. The partial pressure of oxygen is kept unchanged during the evaporation. The thickness of the film was monitored by using a crystal thickness monitor and was reversely checked by using the Tolansky's multiple beam interference technique [21]. The samples were healed in a furnace for 30 minutes at $350^{\circ} \mathrm{C}$ in air. The electrical conductivity of the samples was calculated by using the conductivity cell and a Keithley programmable electrometer (model No.617). The ohmic contacts were prepared by pre-evaporated silver electrodes and silver paste. The conductivity measurements were found out in a subsidiary vacuum of $10^{-3}$ mbar to eradicate the contamination of the film.

\section{Results and Analysis}

Figure 1 gives the variations of the resistivity of the thermally evaporated ITO thin films deposited at different substrate temperatures ranging from 100 to $350^{\circ} \mathrm{C}$. The rate of deposition was $10 \mathrm{~nm} / \mathrm{min}$ and the thickness of the film was $150 \mathrm{~nm}$. A sudden decrease in resistivity was obtained in the temperature range between 100 and $250^{\circ} \mathrm{C}$. The lowest resistivity obtained was $2 \times 10^{-6} \Omega \mathrm{m}$ at a substrate temperature of $300^{\circ} \mathrm{C}$. The decrease in resistivity with increase in substrate temperature could be characterised to the improved crystalline nature of the films. An enhancement in substrate temperature resulting in oxygen-deficient films causes an increase in carrier density. To increase the crystallinity, the substrate should be heated during deposition of ITO films. The higher substrate temperature also causes an increase in grain size which decreases the grain boundary scattering. It also forms an oxygen deficient films. These oxygen deficiencies are also responsible for the lower resistivity in the film [15]. At the substrate temperature of $200^{\circ} \mathrm{C}$ the resistivity was $8 \times 10-6 \Omega \mathrm{m}$. From the results, we can found that the optimum substrate temperature for low resistive films is $350^{\circ} \mathrm{C}$. However, the substrate temperature was chosen as $200^{\circ} \mathrm{C}$ in further studies. Figure 2 shows the variation of the resistivity of ITO thin films evaporated at $200^{\circ} \mathrm{C}$ and $150^{\circ} \mathrm{C}$ as a function of deposition rate. It is found that the resistivity exposes strong dependence on the deposition rate. The film of having

The Effect of Deposition Rate on the Electrical Properties of Indium Tin Oxide... (Hadaate Ullah) 
thickness of $150 \mathrm{~nm}$ exhibits a linear increment in the resistivity of more than $200 \%$ from an initial value of $3.10 \times 10^{-6} \Omega \mathrm{m}$ to $9.10 \times 10^{-6} \Omega \mathrm{m}$ for a range of deposition rate from 2 to 10 $\mathrm{nm} / \mathrm{min}$. Similarly an increase in resistivity can be obtained by raising up the deposition rate for a film deposited at $150^{\circ} \mathrm{C}$. These results show that the substrate temperature can be significantly minimized by choosing a minimum rate of evaporation without effecting the film properties. Here, the electrical conductivity studies have been carried out in the temperature region of 30 to $300{ }^{\circ} \mathrm{C}$. The activation energy is obtained by using the relation:

$$
\sigma=\sigma_{0} \exp (-\delta E / k T)
$$

Where,

$\sigma$ is the electrical conductivity,

$\delta \mathrm{E}$ is the activation energy,

$\sigma_{0}$ is a constant,

$\mathrm{k}$ is the Boltzmann constant and

$\mathrm{T}$ is the temperature in absolute scale.

The conductivity studies on films deposited at a substrate temperature of $200^{\circ} \mathrm{C}$ and was deposited at a rate of $10 \mathrm{~nm} / \mathrm{min}$ exhibited that two activation energies existed at different temperature regions. The activation energy in the lower temperature region $\left(30-130^{\circ} \mathrm{C}\right)$ for a film of thickness of $150 \mathrm{~nm}$ was $0.041 \mathrm{eV}$ and was $0.453 \mathrm{eV}$ in the higher temperature region (130$220^{\circ} \mathrm{C}$ ). The activation energies obtained for different films deposited at various deposition rates is as shown in Table 3. The results indicated the presence of two donor levels, one deep and one shallow, near the bottom of the conduction band. Hoffman has enlisted the activation energies as 0.035 and 0.045 in the corresponding regions respectively [23]. Both levels were depended on the deposition rate and were found to be decreased with decreased deposition rate. The results show that the film tends to complete degeneracy state as the deposition rate is decreased.

Table 1. Resitivity at different temperature.

\begin{tabular}{cc}
\hline Substrate Temperature $\left({ }^{0} \mathrm{C}\right)$ & Resistivity $\left(\times 10^{-6}\right) \Omega \mathrm{m}$ \\
\hline 100 & 200 \\
150 & 30 \\
200 & 8 \\
250 & 3 \\
300 & 2 \\
350 & 1 \\
\hline
\end{tabular}

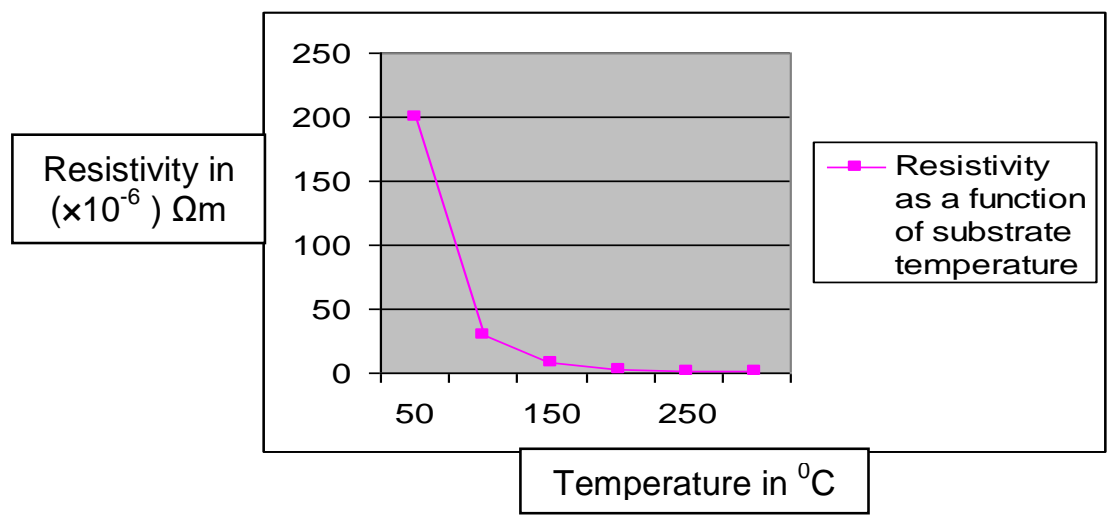

Figure 1. Resistivity as a function of substrate temperature 
Table 2. Resistivity at different rate of deposition for $200^{\circ} \mathrm{C}$ and $150^{\circ} \mathrm{C}$ temperature.

\begin{tabular}{ccc}
\hline Rate of deposition $(\mathrm{nm} / \mathrm{min})$ & Resistivity $\left(\times 10^{-6}\right) \Omega \mathrm{m}$ at $200^{\circ} \mathrm{C}$ & Resistivity $\left(\times 10^{-6}\right) \Omega \mathrm{m}$ at $150^{\circ} \mathrm{C}$ \\
\hline 2 & 3.10 & 7.53 \\
4 & 4.55 & 9.05 \\
6 & 6.12 & 10.52 \\
8 & 7.51 & 11.95 \\
10 & 9.10 & 13.53 \\
\hline
\end{tabular}

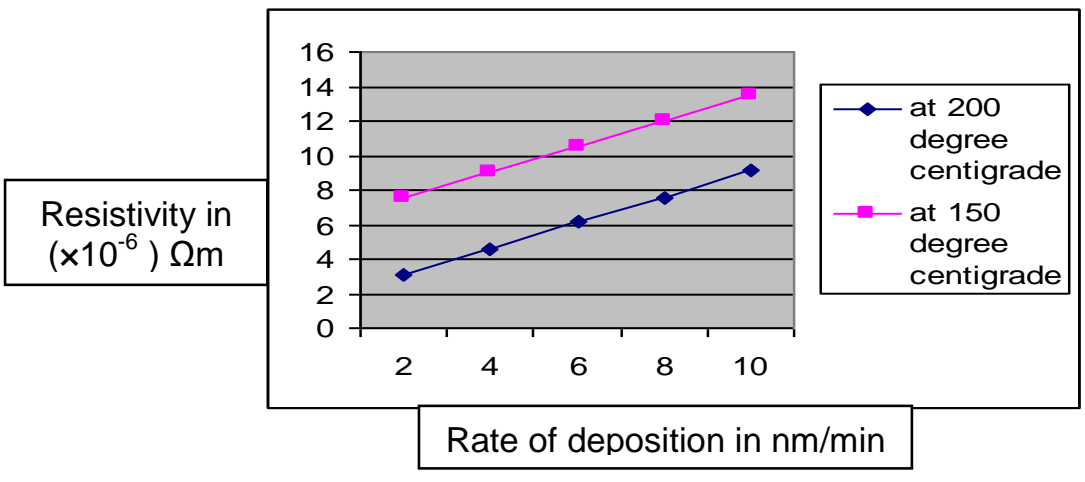

Figure 2. Change of resistivity of ITO thin films as a function of deposition rate for substrate temperature at $150^{\circ} \mathrm{C}$ and $200^{\circ} \mathrm{C}$.

Table 3. Activation energies of various films.

\begin{tabular}{ccc}
\hline Rate of deposition $(\mathrm{nm} / \mathrm{min})$ & Activation energy $(\mathrm{eV}), \Delta \mathrm{E}_{1}$ & Activation energy $(\mathrm{eV}), \Delta \mathrm{E}_{2}$ \\
\hline 2 & 0.021 & 0.351 \\
4 & 0.024 & 0.379 \\
6 & 0.031 & 0.400 \\
8 & 0.039 & 0.421 \\
10 & 0.041 & 0.453 \\
\hline
\end{tabular}

\section{Conclusion}

ITO thin films of high conductivity can be obtained by changing the deposition rate and high quality films with resistivity as low as $3 \times 10^{-6} \Omega \mathrm{m}$. The resistivity decreases with the increasing temperature in exponential form and linearly increases with the increasing deposition rate. The activation energies were calculated to be $0.031 \mathrm{eV}$ and $0.400 \mathrm{eV}$ for a film of thickness $150 \mathrm{~nm}$ and deposited at a rate of $6 \mathrm{~nm} / \mathrm{min}$. It is noted that the activation energy at higher temperature is more than at lower temperature for the same deposition rate.

\section{References}

[1] Eisgruber I, Engel J, Hollingsworth R, Rhat P. Vacuum Thin Film Technol. 1999; 6: 21-25.

[2] Badeker K. Ann. Phys. Leipzig. 1907; 22: 749.

[3] Chopra KL, Major S, Pandya DK. Thin Solid Films. 1983; 102(1).

[4] Rupprecht GZ. Phys. 1954; 139: 504.

[5] Cruz LRO, Santos OJ. Materials Letters. 1991; $12: 72$.

[6] Hongbin Ma, Jung-Soo Cho, Chung-Hoo Park. Surf and Coatings Tech. 2002; 153: 131.

[7] Hirokazu Izumi, Fredirick OA, Takahiro Kaneyoshi, Tsuguo Ishihara, Hideki Yoshika, Muneyuki Motoyama. J. Appl. Phys. 2002; 91: 1213.

[8] Vossen JL. Phys. Thin Films. 1977; 9: 1.

[9] Latz R, Michael K, Scherer M. J.Appl.Phys. 1991; 30: 149.

[10] Bender M, Seelig W, Daube C, Frankenberger H, Ocker B, Stollenwerk J. Thin Solid Films. 1998; 326: 67.

[11] Takaki S, Matsumoto K, Susuki K. Appl.Surf.Sci. 1988; 919: 33-34.

[12] Lee CH, Huang CS. Mater Sci.Eng. 1994; 223: 22.

[13] Pankove JI. Display Devices Topics in Applied Physics. Springer-Verlag, Berlin. 1980; 40.

[14] Kaneko E, Liquid Crystal Displays, KTK Scientific Tokyo. 1987.

[15] Hamberg I, Granquist CG, Berggren KF, Sernelius BE, Engstrom L. Vacuum. 1985; 35: 207. 
[16] Sawada M, Higuchi M. Thin Solid Films. 1998; 317: 157.

[17] Manifacier JC, Szepessy L, Bresse JF. Perotin M and Stuck R Mater. Res. Bull. 1979; 14: 163.

[18] Chopra KL, Major S, Pandya DK. Thin Solid Films. 1983; 102: 1.

[19] Balasubramanian N, Subrahmanyam A. J. Phys. D. Appl. Phys. 1989; 22: 206.

[20] Cali C, Mosca M, Targia G. Solid State Electron. 1986; 42: 877.

[21] Tolansky S. An Introduction to Interferometry. Longmans Green \& Co. Ltd. London. 1955.

[22] Dutta J, Ray S. Thin Solid Films. 1986; 162: 119

[23] Hoffman H, Dietrich A. Pickl J and Krause D Appl. Phys. 1978; 16: 381. 